\title{
Right Lung, Inferior Lobe, Posterior Basal Segment
}

National Cancer Institute

\section{Source}

National Cancer Institute. Right Lung, Inferior Lobe, Posterior Basal Segment. NCI

Thesaurus. Code C132405.

The posterior basal segment of the inferior lobe of the right lung. 